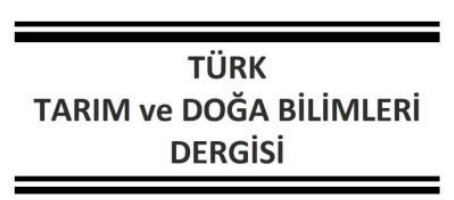

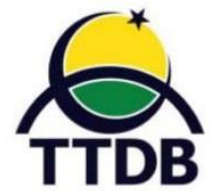

www.dergipark.gov.tr/turkjans
TURKISH

JOURNAL Of AGRICULTURAL and NATURAL SCIENCES

\title{
Araştırma Makalesi \\ Araştırma Makalesi \\ Tarımsal Verimliliğin Arttırılmasında Kamusal Ar-Ge Desteklerinin Etkisi: AB Üyesi Geçiş Ekonomileri Örneği
}

\author{
Mehmet $\mathrm{AKYOL}^{1 *}$, Semanur SOYYiĞiT ${ }^{2}$ \\ ${ }^{1}$ Gümüşhane Üniversitesi, iliBF, Iktisat Bölümü, Gümüşhane \\ ${ }^{2}$ Kırklareli Üniversitesi, IïB, Maliye Bölümü, Kırklareli \\ *Sorumlu Yazar: makyol@gumushane.edu.tr
}

Geliş Tarihi: 24.04.2020, Düzeltme Geliş Tarihi: 08.12.2020, Kabul Tarihi: 11.01.2021

\section{Öz}

Dünyada yaşanan fiziksel, çevresel ve siyasal olaylar tarım sektörünün önemini arttırmaktadır. Gelişmiş ülkeler kadar gelişmekte olan ülkeler de tarımsal üretimi ve verimliliği arttırmak adına bir dizi politika uygulamaktadır. Bu politikalardan biri de tarımsal Ar-Ge faaliyetleridir. Bu çalışmada kamu tarafından desteklenen tarımsal Ar-Ge harcamalarının tarımsal verimlilik üzerindeki etkisi analiz edilmiştir. 2004 yılı sonrasında AB üyesi olan ve geçiş ekonomileri olarak adlandırılan Kıbrıs, Çekya, Estonya, Macaristan, Letonya, Litvanya, Slovakya ve Slovenya analize dahil edilmiştir. 2005-2016 yılları arası dönemi kapsayan çalışmada, tarımsal üretime yönelik kamusal Ar-Ge harcamalarının tarımsal verimlilik üzerinde kısmen pozitif etki oluşturduğu sonucuna ulaşılmıştır.

Anahtar kelimeler: Ar-Ge, kamusal destekler, tarımsal verimlilik

\section{The Impact of Public R\&D Supports on the Increase of Agricultural Productivity: The Case of the EU Member Transition Economies}

\begin{abstract}
Physical, environmental and political events in the world, increase the importance of the agricultural sector. Developing countries, as well as developed countries, implement a number of policies to increase agricultural production and productivity. One of these policies is agricultural R\&D activities. In this study, the effect of publicly supported agricultural R\&D expenditures on agricultural productivity was analyzed. Cyprus, Czechia, Estonia, Hungary, Latvia, Lithuania, Slovakia and Slovenia, which are called transition economies and became a member of the European Union in 2004, were included in the analysis. In the study covering the period between 2005 and 2016, it was concluded that public R\&D expenditures for agricultural production had a partial positive effect on agricultural productivity.
\end{abstract}

Key words: R\&D, governmental aids, agricultural productivity

\section{Giriş}

Tarım sektörü tarihte olduğu kadar günümüzde de önemini korumaktadır. Yerleşik hayata geçilmesi ile birlikte insanoğlu artan gıda intiyacını karşılamak amacıyla toplayıcılıktan tarımsal faaliyetlere yönelmeye başlamış, sonraki dönemlerde ise toplumsal hayatın dönüşümü, değişen ve gelişen yaşam koşulları tarımsal üretimin enerji, yakıt, tekstil ve tarıma dayalı kimyasal materyallerin üretiminde hammadde olarak kullanıımasına imkân sağlamıştır (Alston ve Pardey,
2014). Günümüzde artan dünya nüfusu, ülkeler arasında yaşanan siyasi belirsizliklerin neticesinde ortaya çıkan çatışmalar, iklim değişikliği, doğal afetler sonucu kaybedilen tarımsal araziler ve benzeri olumsuzluklar da tarımsal üretimin önemini geçmişe nazaran daha da arttırmıştır. Tarımsal üretim sürecini etkileyen ve toplam çıktının azalmasına neden olan olumsuzluklar, gelişmiş ülkelerde olduğu kadar gelişmekte olan ülkelerde de 
tarımsal üretimde verimlilik kavramını ön plana çıkarmıştır.

Tarımsal üretimde verimlilik kavramı ilk olarak Schultz (1956) tarafından ortaya atılmıştır. Schultz'a göre eğitim faaliyetlerine daha fazla önem verilerek deneyimin arttırılması yolu ile beşeri sermayenin iyileştirilmesi, bilimsel ve teknolojik ilerlemeler, iş geliştirme süreçlerinin üretime uygulanması, araştırma enstitülerinin kurulması ve bilimsel çalışmaların hızlandırılması gibi faaliyetler üretimde verimliliğin temelini oluşturmaktadır. Diğer yandan Griliches (1957) de tarımda teknolojik değişimin etkisini ifade ederek bu süreçte verimlilik artışlarının bu alandaki önemli yatırımlarla gerçekleştirileceğini, ayrıca kamu ve özel sektörün kaynakları bu alana yönlendirmesiyle üretimin ve karlılığın arttırılacağını ifade etmektedir. İnovasyon ve teknolojik ilerlemeye bağlı olarak tarım sektöründe meydana gelen değişimler bir yandan tarımsal dönüşüme öncülük ederken diğer yandan da milli gelir artışı sağlayarak gelirin toplumda adil paylaşımına imkân verirken üretim faktörleri üzerinde de pozitif iktisadi sonuçlar ortaya koymaktadır (Alston ve ark., 2009).

Tarımsal verimliliğin artmasında önemli bir faktör inovasyon faaliyetleridir. Yeni ürün ve üretim yöntemlerinin geliştirilmesi olarak tanımlanan inovasyonun hayata geçirilmesi ise ancak etkin ArGe çalışması ile mümkün olmaktadır. Diğer sektörlerde olduğu gibi tarım sektöründe de etkin Ar-Ge çalışması üretim süreçlerinin geliştirilmesinde rol oynarken aynı zamanda tarımsal dönüşümü gerçekleştirerek ekonomik gelişime de katkı sağlamaktadır (Alston, 2018). Uluslararası rekabet gücünün arttırılması, sanayi sektörüne düşük maliyetli hammadde sağlanması, ithal ikameci üretim stratejisi geliştirerek döviz girdisi elde edilmesi ve gıda güvenliğinin temini gibi nedenler de tarımsal Ar-Ge faaliyetlerinin önemini gözler önüne sermektedir.

Tarımda Ar-Ge harcamalarının arttırılması ile hedeflenen, çeşitli nedenlerle tarımsal üretimde verimliliğin düşmesinin engellenmesidir. Örneğin; iklim şartlarında meydana gelen ani değişimler, tarım arazilerinde ortaya çıkan bozulma ve aşınmalar, tarımsal girdi fiyatlarındaki artışlar, tarımsal zararlılar ve hastalıklar tarımsal üretimde verimliliği azaltan faktörler arasında yer almaktadır (Alston ve ark., 2009). Ayrıca, kamu ve özel sektör tarafından gerçekleştirilen Ar-Ge harcamaları, tarımsal verimlilik artışına imkân sağlamaktadır. Nitekim 1990 yılından günümüze kadar geçen sürede tarımsal çıktının dörtte üçlük kısmı verimlilik artışından elde edilirken sadece dörtte birlik kısmı ise üretimde kullanılan tarımsal girdilerin arttırılmasından elde edilmiştir (Heisey ve Fuglie, 2018). Diğer yandan tarımsal üretimde verimlilik, çıktı düzeyinde artış sağlamakta ve yerli tarımsal endüstrilerin uluslararası rekabet güçlerini arttırmaktadır. Bir başka ifade ile tarım sektörünün rekabet gücü ile verimlilik arasında yakın bir ilişkiden söz etmek mümkündür (Sheng ve ark., 2011).

2018 yılı verilerine göre; dünya genelindeki tarımsal arazilerin yarısı erozyon ve çölleşmeye bağlı olarak verimliliğini yitirmiş ve bu durum 400 milyar dolarlık gelir kaybına neden olmuştur. Gelişmekte olan ülkelerde 2005-2015 yılları arasında doğal afetler nedeniyle zarar görmüş tarımsal ürünlerin ve hayvansal bitkilerin ekonomik değeri 96 milyar dolara ulaşmıştır. Dünya genelinde 56 milyon insan çatışma alanlarında yaşamakta olup acilen gıda yardımına ihtiyaç duymaktadır (GAP, 2019). Yukarıda bahsi geçen çevresel ve siyasal gelişmeler dünya genelinde tarımsal verimliliğin ve üretimin azalması sonucunda toplumların karşı karşıya kaldığı refah kaybı ve gıda yetersizliğine örnek teşkil etmektedir. Özellikle gelir seviyesinin yüksek olduğu kentsel alanlarda nüfusun gıda intiyacının sağlanması ve bu ihtiyacın giderilmesinde sürdürülebilirliğin ön planda tutulduğu ve doğal kaynakların tahrip edilmediği verimlilik artışı için tarımsal Ar-Ge harcamaları daha fazla önem kazanmaktadır (Pardey ve ark., 2016).

Tarım sektörüne yönelik Ar-Ge harcamaları kamusal ve özel sektör öncülüğünde gerçekleştirilmekte ve tarımsal üretkenliğe pozitif katkı yapmaktadır. Her iki sektörün Ar-Ge faaliyetlerinin, kamusal Ar-Ge'nin daha çok teknolojik yeniliğe yöneldiği, özel sektör Ar-Ge faaliyetlerinin ise kamu tarafından geliştirilen teknolojik yenilikleri kullanarak yeni ve ticarileştirilmiş ürünler elde ettiği bir durumda, birbirini destekler nitelikte olduğu ileri sürülebilir (Wang ve ark., 2013). Diğer sektörlerde olduğu gibi tarım sektöründe de Ar-Ge harcamalarının ekonomik geri dönüşümü uzun yıllar almaktadır. Yeni üretim yöntemlerinin geliştirilmesi veya birim alandan çok daha fazla tarımsal çıktı elde edilmesi üzerine yoğunlaşan tarımsal Ar-Ge faaliyetleri dolayısı ile verim artışı sağlanması uzun bir zaman dilimi sonucunda gerçekleşmektedir (Kristkova ve ark., 2017). Bu bakımdan kamu tarafından desteklenen tarımsal Ar-Ge harcamaları kâr güdüsünün sıklıkla geri planda bırakıldığı teknoloji geliştirme çabalarına odaklanmaktadır (Alfranca ve Huffman, 2001).

Gelecek dönemlerdeki gıda güvenliğinin kontrol altına alınması zorunluluğu tarımsal Ar-Ge faaliyetlerinin kamu sektörü tarafından 
desteklenmesini zorunlu kılmaktadır. Gıda güvenliği, her geçen gün daha fazla artan oranda tarımsal verimliliğe bağımlı hale gelmektedir. Tarımsal çıktı düzeyindeki artışın ekilebilir arazi gibi geleneksel tarımsal girdilerdeki artıştan kaynaklandı̆̆ı düşünülmemelidir (Andersen, 2015). Her ne kadar yeni tarım arazilerinin açılması ve mevcut arazilerin yoğun şekilde üretime koşulması toplam tarımsal üretimi arttırıyor olsa da bu alternatiflerin çevresel etkileri üretim artışının sürdürülebilirliğini tehdit etmektedir (Tilman ve ark., 2011). Diğer yandan dünya genelinde artan gıda ihtiyacının karşılanması da tarımsal verimliliğin arttırılması gerekliliğini gözler önüne sermektedir (Andersen, 2015). Çeşitli çalışmalar artan gıda ihtiyacının karşılanması için 2050 yılına kadar global gıda üretiminin \%60-\%110 aralığında arttırılması gerektiğini ifade etmektedir (Ray ve ark., 2013; Tilman ve ark., 2011) . Küresel gıda üretiminin gelecek yıllarda çevreye vereceği olumsuz etki ve daha fazla tarımsal çıktı elde ederken bu olumsuz çevresel etkilerin azaltılması için gelecekteki tarımsal ürün talebi ile farklı üretim yöntemlerinin çıktı ve çevre üzerindeki etkisinin nicel olarak değerlendirilmesi gerekir (Tilman ve ark., 2011).

Tarımsal faaliyetler küresel ölçekte önemli çevresel etkiler ortaya koymaktadır. Yeni tarım arazilerinin açılması ve buna bağı olarak tabiatın doğal dengesinin bozulması biyolojik çeşitliliği tehdit etmekte ve sera gazı emisyonunun 3/4'lük kısmını oluşturmaktadır. Bitkisel üretim ve gübreleme ise deniz, tatlı su ve karasal ekosistemi olumsuz şekilde etkileyerek zarar vermektedir (Tilman ve ark., 2011). $\mathrm{Bu}$ gibi olumsuz sonuçlar birçok gelişmiş ülkede politika yapıcıların tarımsal Ar-Ge yatırımlarına daha fazla önem verilmesi gerekliliğini ifade etmektedir. Hava olaylarında ve iklimde meydana gelen ani değişimler, tatlı suya erişimde yaşanan sıkıntılar ve küresel piyasalarda artan fiyat oynaklıkları gibi zorlukların üstesinden gelinebilmesi ancak tarımsal Ar-Ge yatırımlarının hızlandırılmasıyla mümkün olmaktadır (Beintema ve Stads, 2010).

Tarımsal Ar-Ge faaliyetlerinin kamu otoritesi tarafından desteklenmesinin diğer önemli bir nedeni enerji bağımlılığının her geçen gün artmasıdır. Enerji fiyatlarındaki artış ve enerji politikalarındaki değişim tarımsal üretim ve enerji sektörü arasındaki ilişkiyi güçlendirmektedir. Sanayi üretiminde de önemli bir girdi faktörü olan enerjinin bir kısmının tarıma dayalı üretimden elde edilmesi tarımsal üretimin enerji bağlamında önemini arttırmaktadır (Beckman ve ark., 2013). Mısır ve soya fasulyesi benzeri ürünlerin bio enerji üretiminde kullanılıyor olması birim alandan daha fazla tarımsal çıktı elde edilmesine imkân sağlayacak
Ar-Ge harcamalarının arttırılmasını gerekli kılmaktadır. Diğer yandan çeşitli tarımsal ürünlerin enerji üretiminde kullanılması söz konusu ürünlerin fiyatlarını arttırırken, gıda güvenliği ve doğal bitki örtüsü üzerinde olumsuz etkiler oluşturmaktadır (Kristkova ve ark., 2017).

Kamu tarafından tarımsal Ar-Ge faaliyetlerinin desteklenmesinin bir başka nedeni kırsal kesim hayat standartlarının iyileştirilmesidir. Ülke ekonomileri açısından bölgeler arası gelir eşitliğinin sağlanması kalkınmanın ve ekonomik büyümenin temel belirleyicilerinden birini oluşturmaktadır. Kırsal kesimin gelir düzeyinin arttırılması ve kırdan kente göçlerin engellenmesi hem gelişmiş hem de gelişmekte olan ülke politika yapıcılarının önemle üzerinde durduğu siyasi bir meseledir. Tarımsal Ar-Ge harcamaları üretim miktarını arttırma yoluyla kırsal kesimin gelir seviyesine olumlu katkı yapmaktadır. Diğer yandan geliri artan hane halkları kırdan kente göç konusunda çekimser davranmakta ve bu durum dolaylı olarak kent nüfusunun dengesiz bir şekilde artmasını engelleyerek kent yoksulluğunun da önüne geçmektedir (Thirtle ve ark., 2003). Son olarak tarımsal Ar-Ge harcamalarının kamu tarafından finanse edilmesi salt tarım kesiminin refah seviyesinin arttırılması kapsamanın da ötesinde bilgi birikiminin oluşmasına katkı sağlamayı da hedeflemektedir (Barnes, 2001).

Literatürdeki birçok çalışma tarımsal verimlilik artışının belirleyicisi olarak tarımsal Ar-Ge faaliyetlerine yapılan kamusal yatırımları göstermektedir (Fuglie, 2018). Bu bağlamda ABD'de kamusal araştırma faaliyetlerinin ve tarımsal araştırma fonlarının, tarımsal üretimi genişletici aktivitelerin ve ulaşım ağı altyapı yatırımları gibi faktörlerin tarımsal üretkenlik üzerinde olumlu bir etkisi olduğu sonucuna ulaşılırken (Wang ve ark., 2012; Huffman, 2009; Alston ve ark., 2011) Avustralya tarımında tahıl üretimindeki verimliliğin artmasında kamusal Ar-Ge yatırımlarının önemli bir etkisi olduğu ifade edilmektedir (Sheng ve ark. (2011). Bununla birlikte Sheng ve ark., (2011), uzun vadeli tarımsal Ar-Ge yatırımlarının kısa vadeli yatırımlara nazaran daha yüksek getiri sağladığını ileri sürmektedir. Fan ve ark., (2000) ise, Hindistan'da kırsal yoksulluğun giderilmesinde ve verimlilik artışında kamu otoritesi tarafından yapılacak tarımsal Ar-Ge harcamalarının arttırılması gerektiğinin yanı sıra sulama sistemlerinin iyileştirilmesi, kırsal altyapı hizmetlerinin yaygınlaştırılması ve eğitim sisteminin düzenlenmesi gerektiği sonucuna ulaşmıştır. Uruguay'da da tarımsal araştırma faaliyetleri ve verimlilik arasında yukarıdaki örneklere benzer sonuçlar elde 
edilmiştir. Nitekim Bervejillo ve ark., (2012) Uruguay'da tarımsal verimliliğin artışında Tarımsal Araştırma Kurumu'nun önemli olduğunu belirterek diğer ülkelerde verimlilik artışları durma eğilimi gösterirken söz konusu kurum sayesinde Uruguay'da verimlilik artışını sürekli canlı tutmuş ve 30 yıllık sürede tarımsal verimlilik artış eğilimi sergilemiştir.

Yine ABD tarımına yönelik bir başka çalışmada kamu ve özel sektör destekli tarımsal ArGe faaliyetlerinin tarımsal verimliliği arttırdığı ve kamusal Ar-Ge harcamalarının özel sektör Ar-Ge harcamalarını cesaretlendirdiği sonucuna ulaşılırken (Wang ve ark. 2013), Avrupa Birliği ülkelerinde ise durum çok daha farklı seyretmektedir. Nitekim Alfranca ve Huffman (2001)'e göre 7 Avrupa Birliği ülkesinde kamu tarafından gerçekleştirilen tarımsal Ar-Ge harcamaları tamamlayıcı olmaktan ziyade özel sektörü dışlar nitelikte sonuçlar doğurmakta ve kamu sektörünün uygulamaya dönük yeniliklere yönelik Ar-Ge yatırımları özel sektör Ar-Ge yatırımları ile rekabete girmektedir. Yine Alfranca ve Huffman (2001) kamu tarafından ortaya konan tarımsal araştırmaların özelleştirilme çabası ile kamu sektörünün ileriki dönemlerde özel sektör araştırmalarını tamamlayıcı niteliğe sahip olabileceğini belirtmektedir. Andersen (2015) ise son yillarda ABD'de kamusal Ar-Ge harcamalarındaki artışın gösterdiği azalma eğiliminin verimliliği azaltarak artan gıda ihtiyacının karşılanmasında çeşitli sorunları gündeme getireceği vurgulamıştır.

Tarımsal Ar-Ge harcamaları genelde iki grupta ele alınmaktadır. Bu harcamaların ilki verimliliğin arttırılmasını hedeflerken diğeri ise mevcut üretim miktarının ve verimliliğin azalmasını engellemeyi hedeflemektedir. Bu bağlamda Sparger ve ark. (2013) $A B D^{\prime}$ de üretim miktarı ve verimlilikteki azalmayı engelleyici araştırma harcamalarının genel Ar-Ge harcamaları içerisindeki payını analiz ettikleri çalışmada 1986 yılında Ar-Ge harcamalarının \%35'lik kesiminin üretim miktarını ve verimliliği korumaya yönelik araştırma harcamalarından oluştuğunu 2008 yılına gelindiğinde bu oranın \%41 seviyesine çıktığını belirtmiştir. Elde edilen sonuç yıllar itibari ile üretim miktarını ve verimliliği korumaya yönelik araştırma harcamalarının artış sergilediğini ve bu artışta iklim değişikliğinin, böcek ve patojen kontrolünün ve tarımsal üretim tercihlerinin üretim miktarını ve verimliliği korumaya yönelik araştırma harcamalarını etkilediğini göstermektedir.

Tarımsal Ar-Ge harcamaları ve toplam faktör verimliliği arasındaki ilişki literatürde değinilen konular arasında yer almaktadır (Gutierrez ve
Gutierrez, 2003; Suphannachart ve Warr 2011). Her iki çalışma da sırasıyla Tayland ve 47 gelişmekte olan ülkede tarımsal Ar-Ge harcamalarının toplam faktör verimliliğini pozitif yönde etkilediği sonucuna ulaşmıştır. Bulgular kamu destekli tarımsal Ar-Ge harcamalarının toplam faktör verimliliğinin önemli bir belirleyicisi olduğu ve araştırma faaliyetlerine ayrılan kamusal desteklerin toplam faktör verimliliğini pozitif yönde etkilediğini göstermektedir. Araştırma faaliyetlerinin uluslararası düzeyde yayılım hızı da toplam faktör verimliliğine katkı yapmaktadır. Fuglie (2018) kamu tarafından tarımsal araştırmalara ayrılan payın gelişmiş ülkelerde gelişmekte olan ülkelere nazaran tarımsal toplam faktör verimliliğini daha fazla etkilediğini göstermiştir. Diğer yandan çalışma sonuçları, tarımsal üretimin her ne kadar yerel çevresel şartlara bağlı olsa da ülkeler arası Ar-Ge yayılımının verimlilikte önemli bir rol oynadığını ve tarımsal verimliliğin artış eğilimi sergilemesinin tarımsal Ar-Ge yatırımlarının artışına bağlı olduğunu göstermiştir. Her ne kadar Fuglie (2018) tarımsal araştırmalara ayrılan payın gelişmiş ülkelerde diğerlerine nazaran toplam faktör verimliliği anlamında daha etkin olduğunu ileri sürse de Heisey ve Fuglie (2018)'e göre gelişmiş ülkelerde tarımsal Ar-Ge faaliyetlerine yapılan yatırımların hızı gelişmekte olan ülkelerdeki yatırımlarla kıyaslandığında daha düşük seviyelerde ölçüldüğünü belirterek gelişmiş ülkelerde tarımsal Ar-Ge harcamalarının 2008-2009 yıllarında yaşanan global finansal krize bağlı olarak azalma gösterdiğini tespit etmiştir. Bunun da ötesinde küresel krize kadar gelişmiş ülkelerde tarımsal Ar-Ge harcamalarının tarımsal GSYH'dan daha hızlı bir büyüme sergilediği ve gelişmiş ülkelerde kamu tarafından gerçekleştirilen tarımsal Ar-Ge harcamalarının toplam Ar-Ge harcamaları içindeki payının tarımsal çıktının toplam çıktı içerisindeki payından daha fazla olduğu ifade edilmiştir. Heisey ve Fuglie (2018)'nin çalışması İtalyan tarım sektörünün analiz edildiği ve Esposti ve Pierani (2003) tarafından yapılan çalışmayı da doğrular niteliktedir. Esposti ve Pierani (2003) Italyan tarım sektöründe 1960 ve 1970’li yıllarda kamusal Ar-Ge yatırımlarının azaldığını, 1980 ve 1990'lı yıllarda ise durumun tersine döndüğünü belirtmektedir. Yine son yıllarda tarımsal Ar-Ge harcamalarının azalma eğilimi göstermesinin nedeni olarak ise önceki yıllarda yapılan kamusal araştırma harcamalarının getirisinin beklenilenin altında kalması gösterilmektedir.

Literatür incelemesi konunun önemini ve konuya olan ilgiyi ortaya koymaktadır. Bu çalışmada ise tarımsal Ar-Ge desteklerinin tarımsal verimlilik üzerinde bir etki oluşturup oluşturmadığının tespiti 
amacıyla, AB'nin 2004 yılındaki genişlemesi ile birliğe üye olan ülkeler seçilmiştir. Çalışma döneminin veri erişilebilirliği nedeniyle 2005-2016 dönemi ile sınırlı olması, çalışmanın kısıtlarını oluşturmaktadır. Tarımsal verimliliğin ölçülmesinde tarımsal katma değer verileri sıklıkla kullanılmaktadır. Amaç, üyelik sonrası $A B$ tarım politikası kapsamında bu ülkelerde uygulanmaya başlanan politikaların tarımsal verimlilik üzerinde ne tür bir etki oluşturduğunu incelemektir. Bu amaçla izleyen bölümlerde öncelikle kullanılan materyal ve izlenen yöntem açılanmakta, daha sonra elde edilen bulgular sunulmakta ve son olarak elde edilen sonuçlar tartışılmaktadır.

\section{Materyal ve Yöntem}

Tarımsal verimliliğin ölçülmesinde, CobbDouglass tipi bir üretim fonksiyonundan hareket edilmektedir. Cobb-Douglass üretim fonksiyonu kullanılan üretim faktörleri ile elde edilen çıktı arasındaki ilişkiyi analiz etmede kullanılan ve aynı zamanda ölçeğe göre getiri hakkında da fikir sunan bir fonksiyondur (Küçük, 2011). Eşitlik (1)'de yer alan denklem kullanılmaktadır:

$$
Y=A L^{\alpha} T^{\beta}
$$

Eşitlik (1)'de A, $\alpha$ ve $\beta$ parametreler; $L$ ve $T$ ise üretim üzerindeki etkisi incelenen bağımsız değişkenlerdir. Analizde kullanılan değişkenlere ve veri kaynağına ilişkin detaylı bilgi Çizelge 1'de sunulmaktadır.

Çizelge 1. Değişkenler ve veri kaynağı

\begin{tabular}{|c|c|c|}
\hline Değişken & Değişkene ait açıklama & Veri kaynağı \\
\hline $\log Y$ & $\begin{array}{l}\text { Tarım, orman ve balıkçılık sektöründe işçi başına katma değerin (2010 } \\
\text { fiyatlarıyla, ABD Doları) logaritması }\end{array}$ & Dünya Bankası \\
\hline $\log A$ & $\begin{array}{l}\text { Tarımsal Ar-Ge'ye hükümet desteğinin (yerleşik başına Euro) } \\
\text { logaritması }\end{array}$ & Eurostat \\
\hline LogL & $\begin{array}{l}\text { Tarım kesimindeki istihdamın toplam istihdam içindeki payının } \\
\text { logaritması }\end{array}$ & Dünya Bankası \\
\hline LogT & Tarımsal arazinin toplam içindeki payının logaritması & Dünya Bankası \\
\hline
\end{tabular}

Eşitlik (1)'de yer alan denklemin logaritması alındığında Eşitlik (2) elde edilmektedir:

$$
\log Y=\log A+\alpha \log L+
$$

\section{$\beta \log T \quad(2)$}

Eşitlik (2)'de yer alan modelde LogA katsayısı teknolojik gelişmeyi $\alpha$ ve $\beta$ parametreleri ise sırayla üretimin işgücü ve tarımsal arazi esnekliğini temsil etmektedir. Analiz AB'nin 2004 genişlemesi ile birliğe dahil olan ülkeleri kapsamakla birlikte, Polonya'nın tarımsal Ar-Ge'ye hükümet desteği değişkeninde, Malta'nın ise tarımsal verimlilik değişkeninde veri erişilebilirliğinin kısıtlı olması nedeniyle, analize Kıbrıs, Çekya, Estonya, Macaristan, Letonya, Litvanya, Slovakya ve Slovenya dahil edilebilmiştir. Analiz 2005-2016 dönemini kapsamaktadır. Bu dönemde bahsi geçen ülkelerin söz konusu değişkenler açısından sahip oldukları değişimi izlemek için ilk olarak Şekil 1'de tarım, ormancılık ve balıkçılık sektöründe işçi başına verimlilik değerleri verilmektedir.

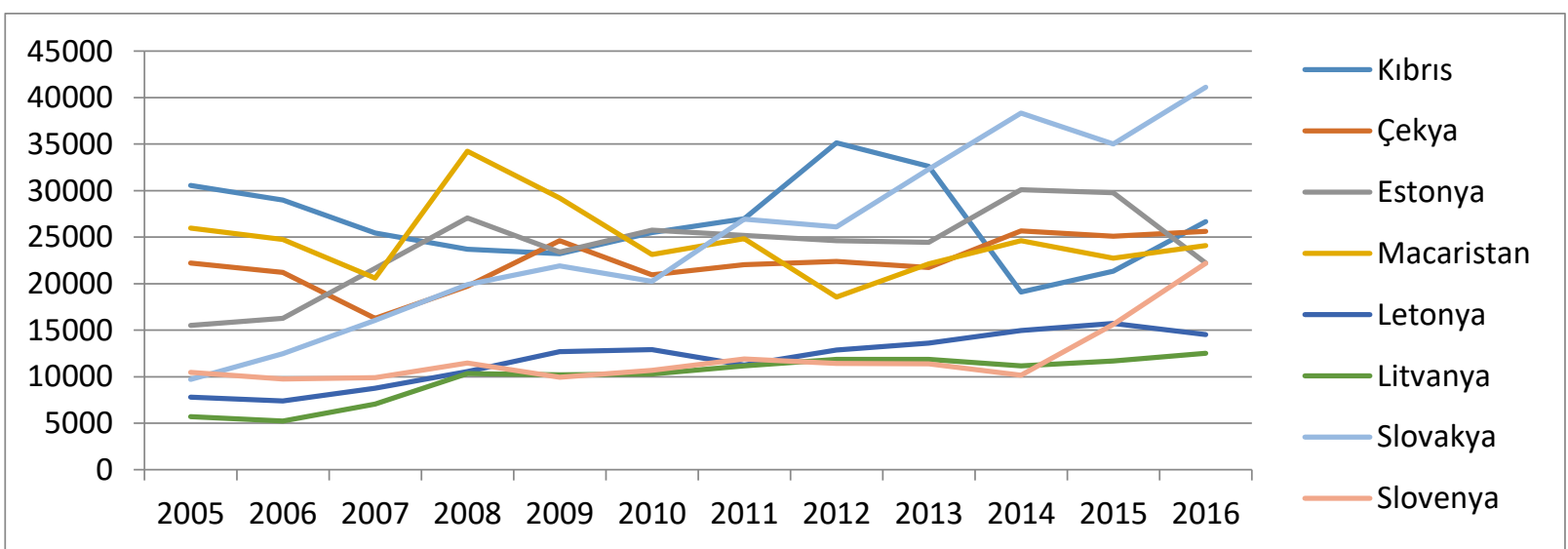

Şekil 1. Tarım, ormancılık ve balıkçılık sektörü çalışan başına katma değer (US\$̦, 2010 fiyatlarıyla) 
Şekil 1 incelendiğinde; Slovakya, Litvanya, Slovenya, Letonya, Çekya ve Estonya'da dönem boyunca işçi başına tarımsal verimliliğin arttığı görülmektedir. Buna karşılık Macaristan ve Kıbrıs'ta tarımsal verimlilik dönem boyunca azalmaktadır.

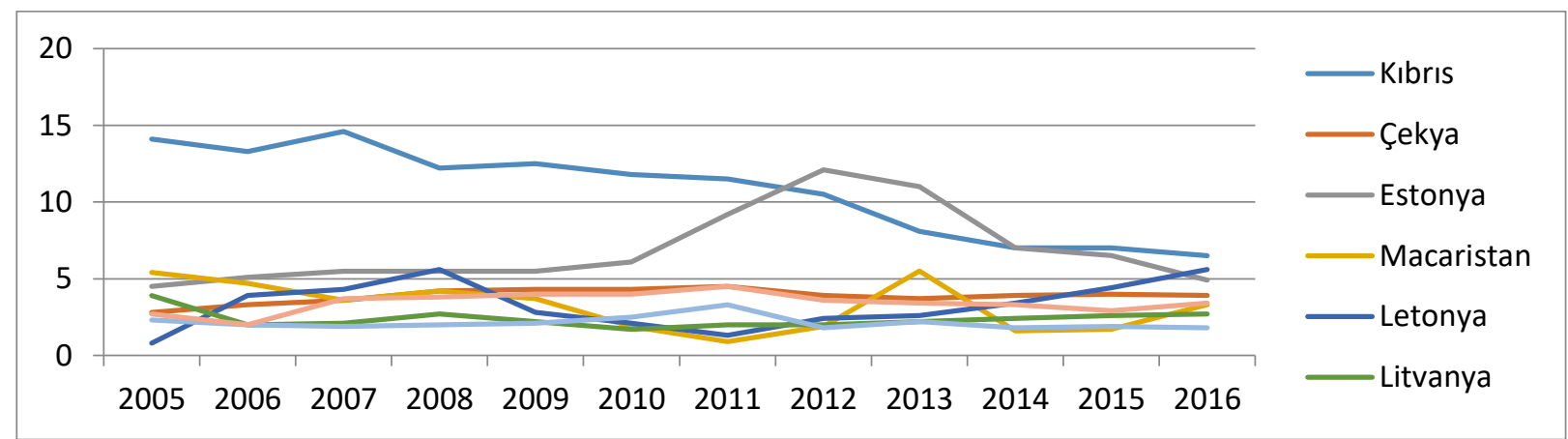

Şekil 2. Tarımsal Ar-Ge'ye Hükümet Desteği (Yerleşik başına, Euro)

Şekil 2'de tarımsal Ar-Ge'ye yerleşik başına hükümet desteğinin zamansal değişimi verilmektedir. Şekilde Kıbrıs'ta bu göstergenin oldukça hızlı bir düşüş gösterdiği görülmektedir. Buna karşılık, Estonya'da da diğer ülkelere kıyasla fark edilir bir artış sergilediği görülmektedir. Macaristan ve Litvanya'da da bir düşüş eğilimi gözlenirken; Slovenya, Çekya ve Letonya'da da artış söz konusudur.

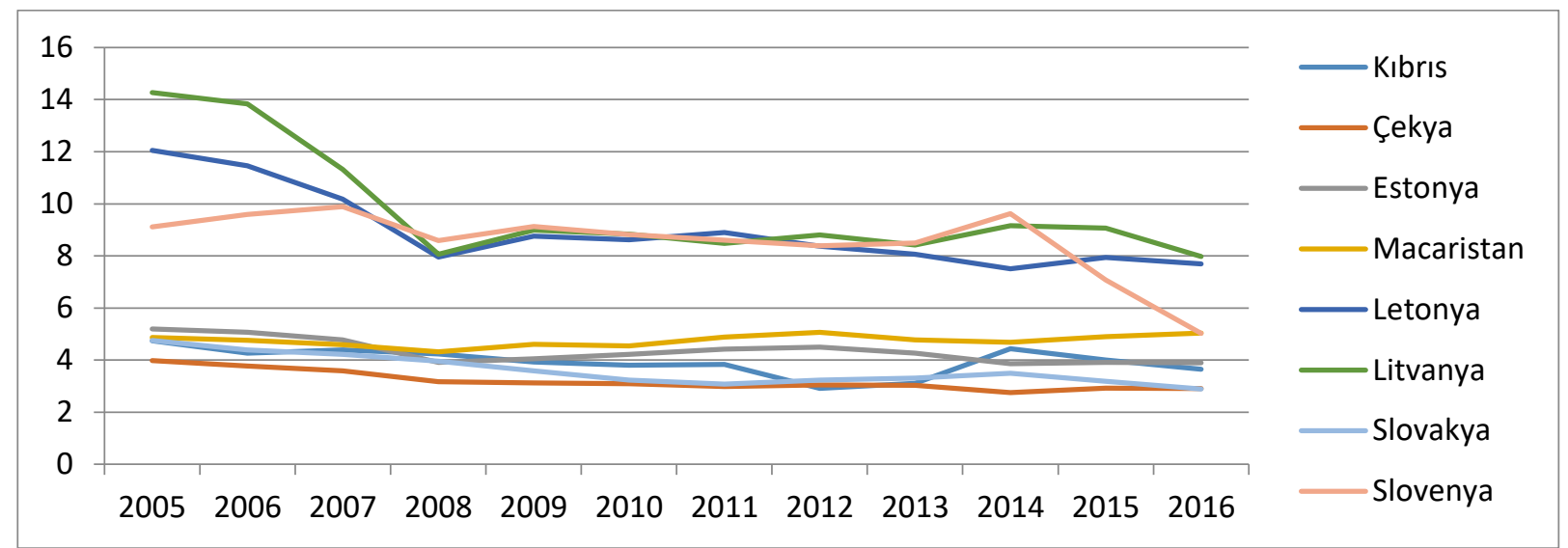

Şekil 3. Tarım istihdamının toplam istihdamdaki payı (\%)

Toplam istihdam içinde tarım istihdamının payının yer aldığı Şekil 3 incelendiğinde, Letonya, Litvanya ve Slovenya'da 2005-2016 dönemi boyunca yüksek oranlara sahip bu göstergenin önemli düzeyde azalış gösterdiği görülmektedir. Litvanya'da 2005 yılında \%12.8 olan bu oran 2016 yılında 7.8'e;
Letonya'da \%11.1'den \% 7.3'e; Slovenya'da ise \%9.7'den \%6.9'a düşmüştür. Esasen, Macaristan dışındaki diğer ülkelerde de bu oranın azalış sergilediği söylenebilir. Macaristan'da ise 2005 yılında \%4.6 olan bu oran, 2016 yılında yaklaşık \%5'e yükselmiştir. 


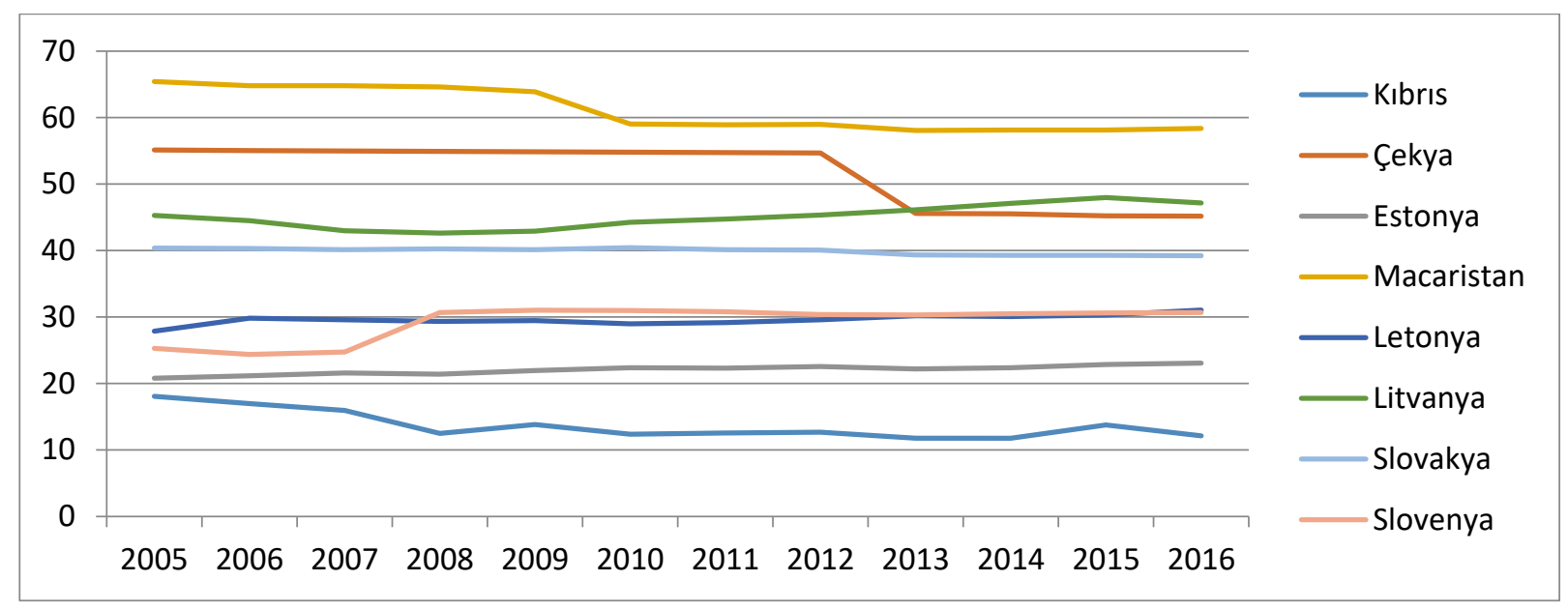

Şekil 4. Tarımsal arazinin toplam içindeki payı (\%)

Tarımsal arazinin toplam arazi içerisindeki payının gelişiminin yer aldığı Şekil 4 incelendiğinde ise Litvanya, Letonya, Estonya ve Slovenya'da tarımsal arazi payının arttığı; buna karşılık, Macaristan, Çekya, Slovakya ve Kıbrıs'ta bu payın azaldığı görülmektedir.

Ekonometrik analizlerde, analizde kullanılan serilerin durağanlığı elde edilecek sonuçların güvenilirliği açısından önemli bir unsurdur. Zira durağan olmayan seriler ile yapılan ekonometrik analizler, sahte regresyon sorununa yol açabilmektedir. Bu sebeple, ekonometrik analize başlarken serilerin durağanlığının incelenmesi önem arz etmektedir. Panel veri analizinde durağanlığın tespit edilmesi için kullanılan birim kök testleri, birinci kuşak testler ve ikinci kuşak testler olmak üzere ikiye ayrılmaktadır. Birinci kuşak birim kök testleri birimler arasında korelasyon yani serilerde yatay-kesit bağımlılık olmadığını varsaymaktadır. İkinci kuşak birim kök testleri ise birimlere ait seriler arasında korelasyon yani yatay-kesit bağımlılık olduğunu varsaymaktadır (Yerdelen Tatoğlu, 2013). $\mathrm{Bu}$ sebeple, birim kök testi ile serilerin durağanlığının sınanmasından önce, uygulanacak birim kök testinin seçimi için serilerdeki yatay kesit bağımlılık incelenmelidir.

Ekonometri literatüründe yatay-kesit bağımlılığını test etmek için geliştirilen çeşitli testler bulunmakla birlikte, bunların ilki, Breusch ve Pagan'ın geliştirdikleri Lagrange çarpanı (Lagrange multiplier-LM) testidir. $\mathrm{T}>\mathrm{N}$ iken kullanılan LM testindeki LM istatistiği $\left(\mathrm{CDLM}_{1}\right)$ Eşitlik (3)'te yer almaktadır (Pesaran, 2004):

$$
\mathrm{CD}_{\operatorname{lm}}=\mathrm{CDLM}_{1}=\mathrm{T} \sum_{\mathrm{i}=1}^{\mathrm{N}-1} \sum_{\mathrm{j}=\mathrm{i}+1}^{\mathrm{N}} \hat{\rho}_{\mathrm{ij}}^{2}
$$

Eşitlik (3)'teki $\hat{\rho}_{i j}^{2}, \quad$ kalıntıların ikili korelasyonunun tahminidir ve Eşitlik (4)'teki formül ile hesaplanmaktadır:

$$
\hat{\rho}_{\mathrm{ij}}=\hat{\rho}_{\mathrm{ji}}=\frac{\sum_{\mathrm{t}=1}^{\mathrm{T}} \mathrm{e}_{\mathrm{it}} \mathrm{e}_{\mathrm{jt}}}{\left(\sum_{\mathrm{t}=1}^{\mathrm{T}} \mathrm{e}_{\mathrm{it}}^{2}\right)^{\frac{1}{2}}\left(\sum_{\mathrm{t}=1}^{\mathrm{T}} \mathrm{e}_{\mathrm{jt}}^{2}\right)^{\frac{1}{2}}}
$$

Eşitlik (4)'teki $e_{i t}=y_{i t}-\hat{\alpha}_{i}-\hat{\beta}_{i}^{\prime} x_{i t}$ olarak tanımlanmakta ve $u_{i t}$ hata terimlerinin EKK tahminini temsil etmektedir. LM testi N'in görece olarak küçük ve T'nin yeterince büyük olduğu durumlarda geçerli bir testtir. Breusch ve Pagan, yatay-kesit bağımlılığı olmadığını ifade eden $\mathrm{H}_{0}$ hipotezi altında, $C D_{l m}$ istatistiğinin asimptotik olarak $\chi^{2}$ dağıldığını göstermişlerdir. Bununla birlikte $\quad N \rightarrow \infty$ olduğunda, bu testin uygulanabilirliği ortadan kalktığı için, Pesaran büyük $\mathrm{N}$ ve $\mathrm{T}$ değerleri söz konusu olduğunda, $C D_{l m}$ 'in ölçeklenmiş versiyonu olan Eşitlik (5)'daki test istatistiğinin $\left(\mathrm{CDLM}_{2}\right)$ kullanılabileceğini göstermiştir (Pesaran, 2004):

$\begin{aligned} \mathrm{CD}_{\mathrm{lm}}=\mathrm{CDLM}_{2} & =\sqrt{\frac{1}{\mathrm{~N}(\mathrm{~N}-1)}} \sum_{\mathrm{i}=1}^{\mathrm{N}-1} \sum_{\mathrm{j}=\mathrm{i}+1}^{\mathrm{N}}\left(\mathrm{T} \hat{\rho}_{\mathrm{ij}}^{2}\right. \\ & -1)\end{aligned}$

$\mathrm{Bu}$ testte de N'in büyük, T'nin küçük değerleri için önemli ölçüde ölçek bozulması meydana gelmesi nedeniyle Pesaran, BreuschPagan LM testinin N'in büyük olduğu duruma ilişkin eksikliğini gidermek üzere, LM testinde karesi kullanılan ikili korelasyon katsayılarının kendilerinin kullanıldığı alternatif bir test istatistiği geliştirmiştir (Pesaran, 2004). Ancak, bu test de ortalama ikili korelasyonların sıfır olduğu, fakat birimlere ait ikili korelasyonların sıfırdan farklı olduğu durumlarda güçlü sonuç vermemektedir. Sonrasında, Pesaran ve ark. LM testinin değiştirilmiş bir versiyonu olan sapması düzeltilmiş LM istatistiğini (LMadj) geliştirmişlerdir (Pan ve ark., 2015): 


$$
\mathrm{LM}_{\mathrm{adj}}=\sqrt{\left(\frac{2 \mathrm{~T}}{\mathrm{~N}(\mathrm{~N}-1)}\right)} \sum_{\mathrm{i}=1}^{\mathrm{N}-1} \sum_{\mathrm{j}=\mathrm{i}+1}^{\mathrm{N}} \frac{(\mathrm{T}-\mathrm{k}) \hat{\rho}_{\mathrm{ij}}^{2}-\mu_{\mathrm{Tij}}}{\sqrt{\mathrm{v}_{\mathrm{T} i j}^{2}}}
$$

Yatay kesit bağımlılığın bu testler ile tespitinin ardından, kullanılacak birim kök testi seçilebilir. Bu çalışmada, yatay kesit bağımlılık olmayan seriler için birinci kuşak birim kök testlerinden IPS (Im-Pesaran-Shin) birim kök testi, yatay kesit bağımlıık olan seriler için ise ikinci kuşak testlerden MADF (Multivariate ADF) testi kullanılmıştır.

Birinci kuşak ikinci grup testlerde, ortak bir otokorelasyon katsayısı yerine her birimin kendi otokorelasyon katsayısına sahip olmasına izin verilmektedir. Birinci kuşak ikinci grup testlerden IPS testinde, tüm birimler için zaman serilerine ayrı ayrı birim kök testi uygulanmaktadır. IPS test istatistiği ise birimlere ait ADF test istatistiklerinin ortalaması olarak hesaplanmaktadır. $i=1,2, \ldots, N$ paneldeki yatay-kesit sayısını ve $t=1,2, \ldots, T$ gözlem sayısını göstermek üzere, IPS birim kök testinde Eşitlik (7)'deki modelden hareket edilmektedir (Yerdelen Tatoğlu, 2013):

$$
\Delta \mathrm{Y}_{\mathrm{it}}=\rho_{\mathrm{i}} \mathrm{Y}_{\mathrm{it}-1}+\sum_{\mathrm{L}=1}^{\mathrm{Pi}} \Phi_{\mathrm{iL}} \mathrm{Y}_{\mathrm{it}-\mathrm{L}}+\mu_{\mathrm{i}}^{\prime} \gamma+\mathrm{u}_{\mathrm{it}}
$$

IPS testine ait sıfır hipotezi ve alternatif hipotez aşağıdaki gibidir (Yerdelen Tatoğlu, 2013):

$\mathrm{H}_{0}: \rho_{\mathrm{i}}=1$

$\mathrm{H}_{1}: \rho_{\mathrm{i}}<1$

Buna göre; sıfır hipotezi hiçbir birimin durağan olmadığını, alternatif hipotez ise en az bir birimin durağan olduğunu ifade etmektedir. $t_{\rho i}$ birimlere ait bireysel test istatistiklerini ifade etmek üzere, IPS test istatistiği ise Eşitlik (8)'deki gibi gösterilmektedir:

$$
\bar{t}=\frac{1}{N} \sum_{i=1}^{N} t_{\rho i}
$$

Ikinci kuşak birim kök testlerinden MADF testi ise Taylor ve Sarno tarafından geliştirilmiş bir ikinci kuşak birim kök testidir. Panel verinin zaman boyutu yatay kesit boyutundan büyük olduğunda (T>N) kullanılabilen bir testtir (Brooks, 2014), Taylor ve Sarno, Nx1 boyutlu stokastik vektörden hareket etmişlerdir (Taylor ve Sarno, 1998):

$$
\mathrm{q}_{\mathrm{it}}=\mu_{\mathrm{i}}+\sum_{\mathrm{j}=1}^{\mathrm{k}} \mathrm{p}_{\mathrm{ij}} \mathrm{q}_{\mathrm{it}-\mathrm{j}}+\mathrm{u}_{\mathrm{it}}
$$

Hata teriminin bağımsız olduğu ve normal dağılıma sahip olduğu varsayılan testte, Taylor ve Sarno birimlere ait her bir otoregresif sürecin kökünün 1'e yakın ancak 1'den farklı olduğu durumlarda, tek değişkenli ADF testinin zayıf kalmasından hareketle; Eşitlik (9)'daki denklemi hata terimleri arasındaki eş-anlı korelasyonu dikkate alarak tahmin etmişlerdir. Sıfır hipotezi $\mathrm{N}$ denklem için Eşitlik (10)'daki gibidir (Taylor ve Sarno, 1998):

$\mathrm{H}_{0}: \sum_{\mathrm{j}=1}^{\mathrm{k}} \rho_{\mathrm{ij}}-1=0, \quad \forall \mathrm{i}=1, \ldots, \mathrm{N}$

MADF testi sonucunda elde edilen Wald test istatistiğine aynı zamanda MADF istatistiği de denilmektedir. Eşitlik (9)'daki denklemin tahmininde çok değişkenli genelleştirilmiş kareler yöntemi olarak isimlendirilen Görünürde İlişkisiz Regresyon (SUR-Seemingly Unrelated Regression) yöntemi kullanılmaktadır (Taylor ve Sarno, 1998).

Swamy, sabit katsayı yaklaşımına alternatif olarak, birime ait stokastik spesifikasyonun uygulandığı ve 'rassal katsayılı model' denilen bir regresyon modeli geliştirmiştir. $\mathrm{Bu}$ model, katsayıların birimden birime ve/veya zaman içinde farklılaşmasına izin verirken, aynı zamanda tahmin edilecek parametre sayısını da önemli ölçüde azaltmaktadır (Hsiao ve Pesaran, 2004). Swamy'nin (1970) ifadesini takiben, rassal katsayılı model matris notasyonuyla Eşitlik (11)'deki gibi ifade edilmektedir (Poi, 2003):

$\mathrm{y}_{\mathrm{i}}=\mathrm{X}_{\mathrm{i}} \beta_{\mathrm{i}}+\epsilon_{\mathrm{i}}$

$i=1,2, \ldots N$ yatay kesit boyutunu göstermek üzere, $y_{i}$ i. birime ait olan $T_{i} x 1$ boyutlu gözlem vektörü, $X_{i} T_{i} x k$ boyutlu stokastik olmayan değişken vektörü, $\beta_{i}$ ise i birimine özgü olan $k x 1$ boyutlu parametre vektörüdür. $\epsilon_{i}$ ise sıfır ortalama ve $\sigma_{i i} I$ varyanslıdır. Her bir birime özgü $\beta_{i}$ ise ortak bir $\beta$ parametre vektörü ile ilişkilidir (Poi, 2003): $\beta_{\mathrm{i}}=\beta+\mathrm{v}_{\mathrm{i}}$

Swamy (1970), modelin tahmin edilmesinden önce, $\beta_{i}$ parametre vektörlerinin sabit ve hepsinin eşit olup olmadığını test etmenin doğru olacağını ifade etmiştir. Buna göre test edilecek sıfır hipotez Eşitlik (13)'teki gibi gösterilmektedir:

$\mathrm{H}^{\prime}{ }_{0}: \beta_{1}=\beta_{2}=\cdots=\beta_{\mathrm{n}}=\beta$

$H^{\prime}{ }_{0}$ sıfır hipotezi, katsayı vektörlerinin sabit ve incelenen birimlerin homojen olduğunu, dolayısıyla hipotezin doğrulanması halinde değişkenler arasında tek bir ilişkinin tahmin edilebileceğini ifade etmektedir. Eğer $H^{\prime}{ }_{0}$ hipotezi reddedilirse, bu durumda her bir birime ait verinin değişkenler arasında tek bir ilişkiyi tahmin etmek için havuzlanması mümkün değildir. Homojenliği test etmek için kullanılan istatistik ise Eşitlik (14)'teki formülasyonla gösterilmektedir (Swamy, 1970):

$$
=\sum_{i=1}^{H_{\beta}} \frac{\left(b_{i}-\widehat{\beta}\right)^{\prime} X^{\prime}{ }_{i} X_{i}\left(b_{i}-\hat{\beta}\right)}{s_{i i}}
$$


Eşitlik (14)'te, $b_{i}=\left(X^{\prime}{ }_{i} X_{i}\right)^{-1} X^{\prime}{ }_{i} y_{i}$ ve $\hat{\beta}=$ $\left[\sum_{i=1}^{N} \frac{X_{i}^{\prime} X_{i}}{s_{i i}}\right]^{-1} \sum_{i=1}^{N} \frac{X^{\prime} X_{i}}{s_{i i}} b_{i} \quad$ olarak ifade edilmektedir. Eğer $H^{\prime}{ }_{0}$ hipotezi kabul edilirse, o halde $i=1,2, \ldots N$ olmak üzere, $b_{i}$ de $\beta$ parametre vektörünün $N$ tane sapmasız ve bağımsız tahmincisidir. Özetle, rassal katsayılı panel regresyon modeli tahmin edilmeden önce parametre sabitlik testi uygulanmalıdır.

\section{Araştırma Bulguları}

Çalışmanın bu kısmında, yöntem kısmında açıklanan testlere ait bulgular sunulmaktadır. ilk olarak, Çizelge 2'de yatay kesit bağımlılık testi sonucu görülmektedir.

Çizelge 2. Yatay kesit bağımlılığı testi

\begin{tabular}{lllllll}
\hline \multicolumn{2}{c}{ CDLM1 } & \multicolumn{2}{c}{ CDLM2 } \\
Değişkenler & & & & \multicolumn{2}{c}{ Lmadj } \\
& Test istatistiği & p değeri & Test istatistiği & p değeri & Test istatistiği & p değeri \\
\hline LogY & $91.366^{*}$ & 0.000 & $7.399^{*}$ & 0.000 & $7.035^{*}$ & 0.000 \\
LogA & $46.949^{* *}$ & 0.014 & 1.463 & 0.143 & 1.099 & 0.272 \\
LogL & $129.676^{*}$ & 0.000 & $12.518^{*}$ & 0.000 & $12.154^{*}$ & 0.000 \\
LogT & $147.669^{*}$ & 0.000 & $14.922^{*}$ & 0.000 & $14.559^{*}$ & 0.000 \\
\hline
\end{tabular}

*ve** sırayla 0.01 ve 0.05 anlamlılık düzeyini ifade etmektedir.

Yatay kesit bağımlılık testi sonuçları incelendiğinde $\log Y$, $\log L$ ve $\log T$ değişkenleri için yatay kesit bağımlılık olmadığını ifade eden sıfır hipotezinin reddedildiği, yani bu serilerde yatay kesitler arasında korelasyon olduğu sonucuna varılmaktadır. LogA değişkeni için ise yatay kesit bağımlılık olmadığını ifade eden sıfır hipotezi kabul edilmektedir. Bu sonuçlara dayanarak, LogY, LogL ve LogT değişkenlerine yatay kesit bağımlılığı dikkate alan ikinci kuşak birim kök testlerinden MADF testi uygulanırken, LogA değişkenine ise birinci kuşak birim kök testlerinden IPS testi uygulanmıştır. Birim kök test sonuçları Çizelge 3'te yer almaktadır.

Çizelge 3. MADF birim kök testi

\begin{tabular}{lllll}
\hline Değişkenler & MADF istatistiği & Kritik değer & AIC & BIC \\
\hline LogY & $1042.719^{* *}$ & $236.616(3)$ & -362.361 & -356.05 \\
LogL & $1027.102^{* *}$ & $236.616(3)$ & -449.792 & -443.481 \\
LogT & $4701.261^{* *}$ & $236.616(3)$ & -644.045 & -637.734 \\
IPS birim kök testi & & & Sabit ve trendli model \\
Değişkenler & Sabit model & & Test istatistiği & p değeri \\
& Test istatistiği & p değeri & 0.200 & 0.421 \\
\hline
\end{tabular}

** 0.05 anlamlılık düzeyini ifade etmektedir. Parantez içerisindeki değerler, gecikme uzunluğunu göstermektedir. MADF testinde maksimum gecikme uzunluğu 4 olarak alınmış, uygun gecikme uzunluğunun belirlenmesinde Akaike ve Bayesyen bilgi kriterleri kullanılmıştır.

Parantez içerisindeki değerler, gecikme uzunluğunu göstermektedir. MADF testinde maksimum gecikme uzunluğu 4 olarak alınmış, uygun gecikme uzunluğunun belirlenmesinde Akaike ve Bayesyen bilgi kriterleri kullanılmıştır.

LogY, LogL ve LogT değişkenleri için test istatistiğinin kritik değerden büyük olduğu ve serilerin durağan oldukları görülmektedir. LogA değişkeni için yapılan IPS testi sonucuna göre olasılık değeri sabitli modelde 0.05 'ten küçük ve durağanlığı gösterirken, sabitli ve trendli modelde seride birim kök olduğunu göstermektedir. Sabitli model sonucu dikkate alındığında, analizde kullanılan değişkenlerin tümünün durağan oldukları ifade edilebilir. Ancak, Swamy rassal katsayılı panel regresyon modelinin kullanılabilmesi için, serilerin durağanlığının tespitinden sonra ayrıca Çizelge 4'te yer alan parametre sabitliği testi sonuçları incelenmelidir. 
Çizelge 4. Parametre sabitliği testi.

\begin{tabular}{ll}
\hline $\mathrm{Chi}^{2}$ & p-değeri \\
\hline 249.44 & $(0.000)$ \\
\hline
\end{tabular}

* 0.01 anlamlılık düzeyini ifade etmektedir.

Çizelge 4'teki sonuçlara göre, olasılık değeri 0.05 'ten küçüktür ve katsayı vektörlerinin homojen olduğunu belirten sıfır hipotezi reddedilmektedir. Bir diğer ifadeyle, yatay kesit birimlere ait katsayılar heterojendir. Bu sonuca dayanarak, her bir yatay kesit için ayrı regresyon katsayısı hesaplayan Swamy rassal katsayılı panel regresyon tahmini yapılmış ve sonuçlar Çizelge 5'te sunulmuştur.

Çizelge 5. Swamy rassal katsayılı panel regresyon modeli tahmin sonuçları.

\begin{tabular}{llll}
\hline Ülke & LogA & LogL & LogT \\
\hline Kıbrıs & 0.120 & $-1.308^{*}$ & $0.780^{*}$ \\
& $(0.141)$ & $(0.000)$ & $(0.000)$ \\
Çekya & $-0.495^{*}$ & $-1.423^{*}$ & 0.415 \\
& $(0.000)$ & $(0.000)$ & $(0.247)$ \\
Estonya & $0.184^{* *}$ & $-1.391^{*}$ & 0.732 \\
& $(0.020)$ & $(0.000)$ & $(0.132)$ \\
Macaristan & 0.016 & $-1.416^{*}$ & 0.380 \\
& $(0.859)$ & $(0.000)$ & $(0.566)$ \\
Letonya & $-0.120 * *$ & $-1.403^{*}$ & 1.648 \\
Litvanya & $(0.032)$ & $(0.000)$ & $(0.116)$ \\
& -0.011 & $-1.398^{*}$ & $1.724^{*}$ \\
Slovakya & $(0.897)$ & $(0.000)$ & $(0.000)$ \\
Slovenya & 0.009 & $-1.652^{*}$ & $-16.402^{*}$ \\
& 0.953 & $(0.000)$ & $(0.000)$ \\
\hline
\end{tabular}

* ve ** sırasıyla 0.01 ve 0.05 anlamlılık düzeyini ifade etmektedir.

Çizelge 5'teki sonuçlara göre; tarımsal arazi payının tarımsal verimlilik üzerindeki etkisi Kıbrıs ve Litvanya'da pozitif, Slovakya'da ise negatiftir. Diğer ülkelerde ise söz konusu iki değişken arasında anlamlı bir ilişki söz konusu değildir. Şekil 1 ve Şekil 4 ile birlikte değerlendirildiğinde, bu sonuçların anlamlı olduğu ifade edilebilir. Bu üç ülke arasında Kıbrıs için olumsuz bir durumdan söz edilebilir. Zira Kıbrıs'ta iki değişken arasındaki ilişki pozitif olmakla birlikte, tarımsal arazi payı azalırken, tarımsal verimlilik de azalmıştır. Litvanya'nın dönem boyunca tarımsal arazi payı artmış, bu da tarımsal verimlilik üzerinde pozitif etki ortaya koymuştur. Slovakya incelendiğinde ise tarımsal arazi oranının azalmasına karşılık tarımsal verimliliğin arttığı gözlemlenmektedir.

Tarım istihdamının toplam istihdamdaki payının tarımsal verimlilik üzerindeki etkisi ise bütün ülkelerde negatif ve anlamlı olarak bulunmuştur. Bu sonuçlar Şekil 1 ve Şekil 3 ile birlikte ülke özelinde değerlendirildiğinde ise Macaristan'da iki değişken arasında ilginç bir ilişki olduğu görülmektedir. Dönem boyunca toplam istihdam içerisinde tarım istihdamının payı artarken, iş̧̧i başına verimlilik düşmektedir. Diğer ülkelerde ise (Kıbrıs hariç) tarımsal istihdamın toplam istihdam içindeki payı azalırken, tarımsal işçi başına tarımsal verimlilik artış sergilemektedir. Bu bulgulara dayanarak, Macaristan'da tarım sektöründeki istihdamın verimini olumsuz etkileyen birtakım faktörlerin olduğu çıkarımı yapılabilir.

Çizelge 5'teki sonuçlar içerisinde tarımsal ArGe'ye hükümet desteğinin tarımsal verimlilik üzerindeki etkisine bakıldığında ise Çekya ve Letonya'da negatif, Estonya'da ise pozitif ve anlamlı ilişki olduğu görülmektedir. Diğer ülkelerde ise 
tarımsal Ar-Ge desteğinin tarımsal verimlilik üzerinde anlamlı bir etkisi bulunamamıştır.

\section{Sonuç ve Tartışma}

Tarım sektörü ve tarımsal üretim dünya genelinde önemini arttırmaya devam etmektedir. Özellikle gelişmiş ülkelerde tarımsal üretim ve istihdamın toplam üretim ve istihdam içerisindeki payı azalmakta ise de söz konusu ülkelerde politika yapıcılar tarımsal verimliliği arttırmak veya en azından verimliliğin düşmesini engellemek adına tarımsal üretimi destekleyici politika uygulamalarını sürdürmektedirler. Bu bağlamda bilgiye erişimin kolaylaştığı ve teknolojik ilerlemelerin hız kazandığı son yıllarda yapılan araştırmalar ve ampirik çalışmalar her alanda olduğu gibi tarım sektöründe de tarımsal verimliliğin ve tarımsal üretim miktarının artmasında tarımsal Ar-Ge harcamalarının önemli bir yeri olduğunu göstermektedir.

Ar-Ge faaliyetleri kamu sektörü ve özel sektör olmak üzere iki kaynaktan beslenmektedir. $\mathrm{Bu}$ çalışmada kamu tarafından finanse edilen tarımsal Ar-Ge harcamalarının tarımsal verimlilik üzerindeki etkisi 2004 yılı itibari ile $A B^{\prime}$ ye üye olan ve geçiş ekonomileri olarak adlandırılan ülkeler özelinde analiz edilmiştir. Birçok gelişmiş ülkede olduğu gibi geçiş ekonomileri olarak adlandırılan ülkelerde de tarımsal gelir ve istihdamın toplam gelir ve istihdam içerisindeki payı birkaç ülke hariç azalma eğilimi sergilemektedir.

Tarımsal verimliliğin arttırılmasında kamusal Ar-Ge harcamalarının önemini ilgili alandaki literatür çalışmaları desteklemektedir. Fakat söz konusu harcamaların daha etkin hale getirilmesi kamu kaynaklarının optimal kullanılması açısından önem arz etmektedir. Nitekim kamu otoritesi sağladığı desteklerde önceliği tarım sektörünün gereksinim duyduğu konularda teknolojik altyapının geliştirilmesi ve bilgi birikiminin arttırılmasına vermelidir. $\mathrm{Bu}$ bağlamda yerel araştırma kurumlarının ve özel sektör kuruluşlarının desteklenmesi büyük önem arz etmektedir. Ayrıca tarım sektöründe Ar-Ge faaliyetlerinin geri dönüşü gecikmeli şekilde gerçekleşmekte ve bu süreç uzun zamana yayılmaktadır. Bu bağlamda kamusal Ar-Ge politikalarının belirlenmesi ve uygulanmasında söz konusu gecikme dikkate alınmalıdır. Tarımsal Ar-Ge faaliyetlerinin hedef odaklı, öncelikli ihtiyaçların belirlendiği bir ortamda başarı ile sürdürülmesi hiç şüphesiz alanında uzman insan kaynağına ihtiyacı zorunlu hale getirmektedir. Bu açıdan kamu ile üniversiteler arasındaki iletişim geliştirilmeli ve işbirliği imkânları iyileştirilmelidir. Tarımsal Ar-Ge harcamalarından daha etkin sonuçlar alınmasında tarımsal uygulamaların önemli bir rolü vardır. Özellikle tarımsal üretimde uzmanlaşmanın sağlanması, çiftçilere ve tarım sanayicilerine bilgi ve teknolojideki son gelişmelerin aktarımını sağlayacak eğitici ve öğretici programların hayata geçirilmesi adına uygulanacak politikalar Ar-Ge faaliyetlerinin optimalitesini arttıracaktır. Son olarak Ar-Ge faaliyetlerinin arttırılmasında ve Ar-Ge kapasitesinin geliştirilmesinde kamunun üstlendiği liderlik rolünün yanı sıra sivil toplum kuruluşları, çiftçi birlikleri ve meslek kuruluşları gibi örgütlerin Ar-Ge faaliyetlerine katılımları özendirilmelidir.

Çıkar Çatışması Beyanı: Makale yazarları olarak aramızda herhangi bir çıkar çatışması yoktur.

Araştırmacıların Katkı Oranı Beyan Özeti: Yazarlar olarak makaleye eşit oranda katkı sağlamış bulunmaktayız.

\section{Kaynaklar}

Alfranca O., ve Huffman, W. E. 2001. Impact of institutions and public research on private agricultural research, Agricultural Economics 25, 191-198

Alston, J. 2018. Reflections on agricultural r\&d, productivity, and the data constraint: unfinished business, unsettled issues, Amer. J. Agr. Econ. 100 (2): 392-413.

Alston, J. M., Beddow, J. M., ve Pardey, P. G. 2009. Agricultural research, productivity, and food prices in the long run, Science, 325, 1209-1210.

Alston, J. M., Pardey, P. G., James, J. S. ve Andersen, M. A. 2009. The economics of agricultural r\&d, Annual Review of Resource Economics, 1, 537-566.

Alston, J. M., Andersen, M. A., James, J. S. ve Pardey, P. G. 2011. The economic returns to U.S. public agricultural research, American Journal of Agricultural Economics, 93 (5), 1257-1277.

Alston, J.M., ve Pardey, P.G. 2014. Agriculture in the global economy, Journal of Economic Perspectives 28 (1), 121-146.

Andersen, A. M. 2015. Public investment in U.S. agricultural $r \& d$ and the economic benefits, Food Policy, 51, 38-43.

Barnes, A. P. 2001. Towards a framework for justifying public agricultural $r \& d$ :the example of UK agricultural research policy, Research Policy, 30, 663-672

Beckman, J., Borchers, A. ve Jones, C.A. 2013. Agriculture's supply and demand for energy and energy products, United State Department of Agriculture, Economic Information Bulletin, No.112.

Beintema, M., N. ve Stads, G., J. 2010. Public agricultural $r \& d$ Investments and capacities 
in developing countries recent evidence for 2000 and beyond, IFPRI.

Bervejillo, J. E., Alston, J. M. ve Tumber, K. P. 2012. The benefits from public agricultural research in Uruguay, The Australian Journal of Agricultural and Resource Economics, 56, 475-497.

Brooks, C. 2014. Introductory Econometrics for Finance, 3rd edition, Cambridge University Press, United Kingdom.

Esposti, R. ve Pieroni, P. (2003). Public r\&d investment and cost structure in Italian agriculture 1960-1995, European Review of Agricultural Economics 30 (4), 1-17.

Fan, S., Hazell, P. ve Thorat, S. 2000. Government spending, growth and poverty in rural India, American Journal of Agricultural Economics, 82 (4), 1038- 1051

Fuglie, K. 2018. R\&D Capital, r\&d spillovers, and productivity growth in world agriculture, Applied Economic Perspectives and Policy, 40 (3), 421-444.

Griliches, Z. 1957. An exploration in the economics of technological change, Econometrica, 25 (4), 501-522.

Gutierrez, L. ve Gutierrez, M. M. 2003. International r\&d spillovers and productivity growth in the agricultural sector. a panel cointegration approach, 25th International Conference of Agricultural Economists, August 16-22, Durban, South Africa.

Heisey, P. W. ve Fuglie, K. O. 2018. Public agricultural R\&D in high-income countries: Old and new roles in a new funding environment, Global Food Security,17, 92 102.

Hsiao, C. ve Pesaran, M.H. 2004. Random coefficient panel data models, IZA Discussion Paper, No. 1236.

Huffman, W., E. 2009. Measuring public agricultural research capital and its contribution to state agricultural productivity, lova State University Working Paper No: 09022.

Kristkova, S., Z., Smeets, E. ve Meijl, H. M., 2017. Agricultural $r \& d$ investments, biofuel policy and food security-ACGE analysis, International Congress, August 28September 1, 2017, Parma, Italy 260822, European Association of Agricultural Economists.

Küçük, O. 2011. Faktör esnekliği ve ölçeğe göre getiri: kobilerde karşılaştırmalı bir cobbdouglas üretim fonksiyonu uygulaması, Atatürk Üniversitesi Sosyal Bilimler Enstitüsü Dergisi, 15 (2), 353-362.
Pan, C., Chang, T. ve Wolde-Rufael, Y. 2015. Military spending and economic growth in the middle east countries: bootstrap panel causality test, Defence and Peace Economics 26 (24), 443-456.

Pardey, P. G., Kang, C. C., Dehme, S. P. ve Beddov, J. M. 2016. Agricultural $r \& d$ is on the move, erişim: 06.04.2020 https://www.nature.com/articles/537301a .pdf.

Pesaran, M. H. 2004. General diagnostic tests for cross section dependence in panels, CWPE, 0435.

Poi, B.P. 2003. From the help desk: swamy's random-coefficient model, The Stata Journal, 3 (3), 302-308.

Ray D.K., Mueller N.D., West P.C. ve Foley J.A. 2013. Yield trends are insufficient to double global crop production by 2050. Plos One 8 (6), 1-8.

Schultz, T., W. 1956. reflections on agricultural production, output and supply, Journal of Farm Economics, 38 (3), 748-762.

Sheng, Y., Gray, E. M., Mullen, J. D. ve Davidson, A. 2011. Public investment in agricultural $r \& d$ and extension: an analysis of the static and dynamic effects on Australian broadacre productivity, Australian Bureau of Agricultural and Resource Economics and Sciences, ABARES research report, no: 11.7.

Sparger, J. A., Norton, G. W., Heisey, P. W. ve Alwang, J. 2013. Is the share of agricultural maintenance research rising in the United States?, Food Policy, 38, 126-135.

Suphannachart, W. ve Warr, P. 2011. Research and productivity in thai Agriculture, Australian Journal of Agricultural and Resource Economics 55 (1), 35-52.

Swamy, P.A.V.B. 1970. Efficient Inference in a random coefficient regression model, Econometrica, 38 (2), 311-323.

Taylor, M.P. ve Sarno, L. 1998. The behavior of real exchange rates during the post-bretton woods period, Journal of International Economics, 46, 281-312.

Thirtle, C., Lin, L. ve Piesse, J. 2003. The Impact of research-led agricultural productivity growth on poverty reduction in Africa, Asia and Latin America, World Development 31 (12), 1959-1975.

Tilman, D., Balzer, C., Hill, J. ve Befort, B.L. 2011. Global food demand and the sustainable intensification of agriculture. Proc. Natl. Acad. Sci. 108 (50), 20260- 20264.

Wang, S. L., Ball, V. E., Fulginiti, L. E. ve Plastina, A. 2012. Accounting for the impact of local and spill-in public research, extension, and 
roads on u.s. regional agricultural productivity, 1980- 2004, in productivity growth in agriculture: an international perspective, edited by Keith O. Fuglie, Sun Ling Wang, and V. Eldon Ball, CAB International.

Wang, S. L., Heisey, P. W., Huffman, W. E. ve Fuglie, K. O. 2013. Public $r \& d$, private $r \& d$, and u.s. agricultural productivity growth: dynamic and long-run relationships, Amer. J. Agr. Econ. 95 (5), 1287-1293.

Yerdelen Tatoğlu, F. 2013. Ileri Panel Veri Analizi Stata Uygulamalı, 2. baskı, Beta, İstanbul. 